\title{
DRUG INTERACTIONS AMONG PATIENTS WITH HYPERTENSION TAKING ANGIOTENSIN- CONVERTING ENZYME INHIBITORS IN AN INDONESIAN HOSPITAL
}

\author{
SANTI PURNA SARI ${ }^{1 *}$, AFI FAUZIYAH DARAJAT ${ }^{1}$, BINAR NURSANTI $^{2}$ \\ ${ }^{1}$ Clinical Pharmacy Laboratory, Faculty of Pharmacy, Universitas Indonesia, Depok, 16424, Indonesia. ${ }^{2}$ Division of Pharmacy, Karya Bhakti \\ Pratiwi Hospital, Bogor, 16880, Indonesia. Email: santisari@farmasi.ui.ac.id \\ Received: 29 June 2018, Revised and Accepted: 26 September 2018 and 24 October 2018
}

\begin{abstract}
Objective: This study aimed to analyze the drug interactions associated with angiotensin-converting enzyme (ACE) inhibitors for treating hypertension at Karya Bhakti Pratiwi Hospital between July and December 2016.

Methods: This was an analytical, descriptive, cross-sectional study based on the prescription and medical record data of hospitalized patients treated with an ACE inhibitor and one or more other drugs. Data were included by purposive sampling.

Results: The final analysis was conducted with 120 prescriptions from 71 patients. We found that ACE inhibitors were associated with 139 potential interactions with other drugs in 75 prescriptions (53.96\%); of these, 52 were major interactions and 87 were moderate interactions. The MannWhitney U-test confirmed that the potential drug interactions were significantly associated with polypharmacy ( $<<0.05)$, but the Chi-square test showed no association with either gender or pathophysiology $(\mathrm{p}>0.05)$. Finally, the Kruskal-Wallis test revealed no significant relationship between age and potential drug interactions $(\mathrm{p}>0.05)$.

Conclusion: The final analysis was conducted with 120 prescriptions from 71 patients. We found that ACE inhibitors were associated with 139 potential interactions with other drugs in 75 prescriptions (53.96\%); of these, 52 were major interactions and 87 were moderate interactions. The Mann-Whitney U-test confirmed that the potential drug interactions were significantly associated with polypharmacy ( $<0.05$ ), but the Chi-square test showed no association with either gender or pathophysiology ( $p>0.05)$. Finally, the Kruskal-Wallis test revealed no significant relationship between age and potential drug interactions ( $p>0.05)$.
\end{abstract}

Keywords: ACE inhibitor, Angiotensin-converting enzyme, Drug interaction, Hypertension, Polypharmacy.

(c) 2018 The Authors. Published by Innovare Academic Sciences Pvt Ltd. This is an open access article under the CC BY license (http://creativecommons. org/licenses/by/4. 0/) DOI: http://dx.doi.org/10.22159/ijap.2018.v10s1.29

\section{INTRODUCTION}

Hypertension is a frequently occurring cardiovascular disease [1]. The American Heart Association estimates that it affects 80 million adults in the United States alone. In Indonesia, hypertension is also a prevalent non-communicable chronic disease, which affected $25.8 \%$ of the population in 2013 [2]. Angiotensin-converting enzyme (ACE) inhibitors are a key class of antihypertensive and are the first-line option in certain instances, such as in patients with diabetes or chronic renal failure. These drugs may be administered alone or with other hypertensives for improving efficacy, and they typically need to be taken for long periods $[1,3]$. Combined with the fact that patients treated with ACE inhibitors frequently have comorbidities that also require treatment, these factors increase the potential for drug interactions that can harm the patient.

According to the Micromedex ${ }^{\circledR}$ Interaction Checker, which can be used to check for potential drug interactions, ACE inhibitors have major interactions with 21 other drugs and moderate interactions with 16 other drugs. In some instances of major interactions, medical treatment can be required if they are life-threatening or risk causing permanent damage. Similarly, moderate interactions may require additional therapy for preventing a patient's clinical status from worsening. The following four major factors influence drug interactions: Age, polypharmacy, disease status, and genetics. Literature reviews are required for clarifying the frequency of possible interactions caused by the use of ACE inhibitors and other drugs in patients with hypertension because there is a lack of current data. At Bhakti Pratiwi Hospital, hypertension is among the top 10 most frequently treated diseases, resulting in antihypertensive being prescribed in large quantities.
In this research, we aimed to clarify the rates of major and moderate interactions between ACE inhibitors and other drugs.

\section{METHODS}

We conducted descriptive research using a retrospective crosssectional study design. All data were obtained from prescription and medical records for the period from July to December 2016. The study population comprised all inpatients of Bhakti Pratiwi Hospital who received ACE inhibitors. Data were included if patients were prescribed an ACE inhibitor with one or more other drugs (including other antihypertensive), were aged $\geq 18$ years, and were diagnosed with hypertension. We excluded any data for prescriptions with unclear, incomplete, or untraceable medical records.

After the data were collected, researchers screened the ACE inhibitors against other drugs in the same prescription using the 2017 Micromedex Solution application from Truven Health Analytic, Stockley's Drug Interaction $8^{\text {th }}$ Edition textbook, Drug Interaction Textbook Facts, and related journals. Data were initially analyzed using univariate analysis of age, sex, polypharmacy, and potential interaction data. Subsequently, bivariate analysis was used for determining whether age, gender, polypharmacy, and pathophysiology affected the potential for drug interactions. These four factors were then hypothetically tested using IBM SPSS for Windows, Version 20 (IBM Corp., Armonk, NY, USA). A value of $\mathrm{p}<0.05$ indicated that there was a significant difference between the two variables.

\section{RESULTS AND DISCUSSION}

A total of 155 prescriptions met our inclusion criteria, of which 35 also met the exclusion criteria. Ultimately, 120 prescriptions from 
71 patients were suitable for inclusion. ACE inhibitor was more frequently used in females (59.15\%), patients aged $\geq 60$ years (38.03\%), and those with no impairments of liver or kidney function (36.62\%). Polypharmacy was identified in 67 prescriptions, and most cases received 5-6 drugs (50.75\%). The occurrence of interactions with ACE inhibitors is summarized in Table 1, with 75 of the 120 prescriptions $(53.96 \%)$ having a combined total of 139 interactions (52 were major and 87 were moderate)

\section{Major interactions}

\section{Captopril and allopurinol}

We identified three cases of interaction between captopril and allopurinol (2.16\%). Two patients did not experience hypersensitivity symptoms, but one suffered kidney failure. This result was not comparable to that in other studies, in which eight cases (35.25\%) of such interaction was shown [4]. The mechanism of interaction between captopril and allopurinol is unknown, and it should be considered that allopurinol use alone can cause severe hypersensitivity reactions, especially if the patient has renal failure. Studies conducted by Halevy et al. showed that the using ACE inhibitors and allopurinol were not associated with an increased risk of Stevens-Johnson syndrome and toxic epidermal necrolysis [5].

\section{Captopril and digoxin}

In this study, we identified six cases $(4.32 \%)$ of interaction between captopril and digoxin. The use of digoxin with other drugs requires special attention because digoxin has a narrow therapeutic window of approximately $0.5-2.0 \mathrm{ng} / \mathrm{mL}$; however, this figure is not absolute and varies with individual differences [6]. The interaction of these drugs typically increases plasma digoxin levels because captopril can lead decreases in the glomerular filtration rate and reduced tubular secretion [7]. However, research by Iraz et al. failed to show that a combination of these drugs can increase plasma digoxin levels [6].

\section{Captopril and angiotensin receptor blockers (ARB)}

Two cases were prescribed an ARB and an ACE inhibitor, with one case each $(0.72 \%)$ of interactions for captopril-candesartan and captoprilvalsartan. This may happen probably because doctors and pharmacists

Table 1: Interactions identified between ACE inhibitors and other drugs

\begin{tabular}{ll}
\hline Severity & Occurrence (\%) \\
\hline Major interactions & \\
Captopril and allopurinol & $3(2.16)$ \\
Captopril and digoxin & $6(4.32)$ \\
Captopril and candesartan & $1(0.72)$ \\
Captopril and potassium chloride & $14(10.07)$ \\
Ramipril and potassium chloride & $5(3.59)$ \\
Captopril and cotrimoxazole & $4(2.88)$ \\
Captopril and spironolactone & $16(11.51)$ \\
Ramipril and spironolactone & $2(1.44)$ \\
Captopril and valsartan & $1(0.72)$ \\
Moderate interactions & \\
Captopril and acarbose & $1(0.72)$ \\
Captopril and aspirin & $24(17.26)$ \\
Captopril and mefenamic acid & $1(0.72)$ \\
Captopril and antacid & $2(1.44)$ \\
Captopril and celecoxib & $1(0.72)$ \\
Captopril and dexketoprofen & $1(0.72)$ \\
Captopril and furosemide & $17(12.23)$ \\
Ramipril and furosemide & $4(2.88)$ \\
Captopril and glimepiride & $5(3.59)$ \\
Captopril and gliquidone & $2(1.44)$ \\
Captopril and insulin & $2(1.44)$ \\
Captopril and ketorolac & $11(7.91)$ \\
Ramipril and ketorolac & $1(0.72)$ \\
Captopril and meloxicam & $4(2.88)$ \\
Captopril and metformin & $11(7.91)$ \\
\hline
\end{tabular}

already knew that a combination of these two drugs can harm patients. Hyperkalemia can occur when ACE inhibitors are combined with ARBs. The effect is presumed to occur through each binding to adrenal receptors, interfering with the effects of angiotensin II on aldosterone secretion, and thereby decreasing potassium excretion by the kidney. In a meta-analysis of 33 randomized trials comparing the safety of ACE inhibitors and ARBs alone or in combination, it was reported that concurrent use increased the incidence of hyperkalemia, hypotension events, renal failure, and drug withdrawal by $55 \%, 66 \%, 41 \%$, and $27 \%$, respectively [8]. Interaction between ACE inhibitors and ARBs is rarely identified in studies of drug interactions, making it difficult to find previous research data for comparison with our own.

\section{ACE inhibitors and potassium chloride}

There were 14 cases $(10.07 \%)$ of interaction between captopril and potassium chloride $(\mathrm{KCl})$ and five cases $(3.59 \%)$ of interaction between ramipril and $\mathrm{KCl}$. This differed slightly from two previous studies showing that ACE inhibitor interactions with $\mathrm{KCl}$ resulted in 22 cases (35.85\%) [9] and five cases (27.78\%) [10,11]. ACE inhibitors have a potent retention effect due to decreased aldosterone levels, and this is exacerbated by the addition of supplemental potassium. In practice, increased potassium levels occur clinically only if other factors are present. Retrospective studies of hyperkalemia among inpatients found that the main risk factors were potassium supplementation, severe renal dysfunction, ACE inhibitor/antagonist angiotensin II, use of potassium-sparing diuretics, and diabetes mellitus. Moreover, the presence of two or more of these risk factors was associated with the rapid development of hyperkalemia [12].

\section{Captopril and cotrimoxazole}

Based on this research, there were four cases $(2.88 \%)$ of interaction between captopril and cotrimoxazole. Previous studies have shown that more than half of all patients taking ACE inhibitors were hospitalized for hyperkalemia after taking cotrimoxazole for urinary tract infection [13]. Trimethoprim, a component of cotrimoxazole, has a comparable structure and pharmacology to the potassium-sparing diuretic amiloride. This antibiotic competitively inhibits the potassium channel in the epithelium of the distal nephron, thus interfering with potassium excretion in the kidneys and can lead to hyperkalemia when given in isolation. The combination of cotrimoxazole with an ACE inhibitor significantly increases the risk of hospitalization due to hyperkalemia [14]. Studies have shown that more than half of all patients taking ACE inhibitors were hospitalized for hyperkalemia after taking antibiotics (i.e., cotrimoxazole) to treat a urinary tract infection [13].

\section{ACE inhibitors and spironolactone}

In this study, interactions were observed between captopril and spironolactone in 16 cases $(11.51 \%)$ and between ramipril and spironolactone in two cases (1.44\%). The simultaneous use of these ACE inhibitors with spironolactone can cause hyperkalemia: The ACE inhibitors decrease the amount of aldosterone and cause potassium retention, while spironolactone works additively as an aldosterone antagonist to lower aldosterone levels further [12]. Given that aldosterone is a major hormonal stimulus for potassium excretion in the urine [15], hyperkalemia can occur when its levels decrease. In 2015, another study reported that 1062 patients were treated for hyperkalemia due to combination therapy with an ACE inhibitor and spironolactone [16].

\section{Moderate interactions}

Captopril and nonsteroid anti-inflammatory drugs (NSAIDs)

The total number of cases of ACE inhibitor interactions with NSAIDs was $20(13 \%)$ in this study, which was greater than that reported previously $(\mathrm{n}=35 ; 4.2 \%)$ [17]. Captopril interacts with virtually all NSAIDs, which can cause the effectiveness of captopril decrease. Alone, NSAIDs can increase blood pressure in elderly patients, purportedly through the following mechanisms: (1) Inhibiting enzymes that produce prostaglandins, 
resulting in decreased renal perfusion, (2) increasing sodium and water resistance, and (3) decreasing prostacyclin production.

\section{Captopril and aspirin}

We identified 24 cases (17.26\%) of interaction between captopril and aspirin, comparable to research on drug interactions that identified 33 cases of such interaction [18]. Aspirin may inhibit the effects of ACE inhibitors by inhibiting cyclooxygenase enzymes so that prostaglandins do not form, causing vasoconstriction, decreased cardiac output, and worsening heart failure (Baxter, 2010). The interaction between aspirin and ACE inhibitors has only been reported for high-dose aspirin (2.4 g/day), not low-dose aspirin, and to date.

\section{Captopril and antacid}

There were three cases $(2.16 \%)$ of interaction between captopril and antacids in the present research. In previous research among 10 healthy subjects, antacids were shown to be capable of reducing the area under the curve of single-dose captopril (50 mg) by $40 \%$, albeit without altering the rate of blood pressure decrease. Overall, interactionrelated evidence between ACE inhibitors is limited, and the mechanism by which antacids decrease captopril absorption is unclear and needs further investigation [12].

\section{ACE inhibitors and furosemide}

Based on this research, there were 17 cases (12.23\%) of captopril and furosemide interactions and four cases (2.88\%) of ramipril and furosemide interactions. This was slightly different from data obtained in Iran, where interactions were only reported between ACE inhibitors and furosemide in two patients (0.98\%) [19]. The coadministration of ACE inhibitors with strong diuretics or thiazide diuretics is normally safe and effective, but some patients develop a first-dose hypotensive syndrome (i.e., dizziness, head lightness, and fainting), which occurs when some patients treated for chronic renal failure and taking a high dose of a strong diuretic use an ACE inhibitor for the first time [20]. This hypotension can be aggravated by several conditions, such as heart failure, renovascular hypertension, hemodialysis, high levels of renin and angiotensin, sodium intake, dehydration, diarrhea, vomiting, and hypovolemia, and/or sodium deficiency due to high-dose diuretic use. The risk of hypotension was reported to be greater at furosemide doses $\geq 80 \mathrm{mg}$ daily, so it is recommended that ACE inhibitors should be started in these patients under strict supervision. Clinicians should consider stopping or lowering the doses of diuretics for at least $24 \mathrm{~h}$ before administration. If this is not possible, the response to initial ACE inhibitor administration needs to be monitored for $2 \mathrm{~h}$, or until the blood pressure is stable.

\section{Captopril and antidiabetic medications}

Interactions were observed between captopril and metformin (11 cases; $7.91 \%$ ), captopril and glimepiride (3 cases; $2.16 \%$ ), captopril and acarbose (1 case; $0.72 \%$ ), captopril and gliquidone ( 2 cases; $1.44 \%$ ), and captopril and insulin (2 cases; 1.44\%). Research, in 2015, showed less significant results with up to seven cases of interaction between captopril and insulin and four cases of interaction between captopril and metformin [21]. The mechanism by which ACE inhibitors increase insulin sensitivity remains unclear and is clinically questionable [22]. However, two mechanisms have been proposed. First, captopril may provide a vasodilatory effect which then increases the access of insulin and glucose to skeletal muscle tissue, a key site of insulin-mediated glucose uptake [23]. Second, the increased bradykinin levels associated with ACE inhibitor use may increase vascular permeability and increase the delivery of glucose and insulin to tissues. Although they provided potential mechanisms as to how captopril may improve insulin sensitivity, the researchers failed to show any significant differences between controls and dogs administered captopril and antidiabetic medications simultaneously.

\section{Bivariate analysis}

There was no relationship between sex and potential drug interactions ( $p=0.722$, Chi-square test), consistent with research in Saudi Arabia, which also showed no association ( $\mathrm{p}=0.361$ ) [22]. However, there was a significant relationship between polypharmacy and drug interactions $(\mathrm{p}<0.05$; Mann-Whitney U-test), again consistent with the research from Saudi Arabia $(p<0.001)$ [24]. Increasing the number of drugs administered to a patient increases the potential for drug interactions. This is more common in elderly patients who usually suffer more than one disease, requiring the provision of multiple drugs and increasing the risk of polypharmacy [25].

The Chi-square test results comparing pathophysiology with potential drug interactions also showed that there was no relationship between the two factors $(p>0.05)$. Theoretically, changes in liver and kidney function associated with age produce objective changes in drug clearance and metabolism. For example, as the body ages, blood flow through the liver decreases and the clearance of some drugs can be inhibited by as much as $30-40 \%$ [25]. Some interaction effects will also develop more rapidly if the patient has comorbid renal failure, such as when the patient develops interactions due to captopril-allopurinol, captopril-digoxin, captopril-spironolactone, and captopril-furosemide combinations.

Finally, we use the Kruskal-Wallis tests for assessing the relationship between age and potential drug interaction, which revealed that there was no relationship $(\mathrm{p}=0.071)$. Comparable results were shown in a study of 227 patients $(p=0.99)$ [26]. However, the fact that our results approached significance $(\mathrm{p}<0.05)$, may have been because our age variation was not evenly distributed (e.g., one patient was aged 24 years) and because the cohort was too small to show a relationship (71 patients).

\section{CONCLUSION}

In our hospital from July to December 2016, patients treated with ACE inhibitors for hypertension tended to be female, be aged $\geq 60$ years, have polypharmacy (5-6 drugs), and have no liver or kidney disease. ACE inhibitors were associated with potential interactions with other drugs on 75 prescriptions (53.96\%), with 52 major interactions and 87 moderate interactions identified. The most common interaction was between captopril and aspirin (24 cases, $17.26 \%$ ). The bivariate analyses indicated that there was a relationship between potential drug interactions and polypharmacy $(\mathrm{p}<0.05)$, but that there was no relationship between potential drug interactions and either sex, age, or pathophysiology $(\mathrm{p}>0.05)$.

\section{CONFLICTS OF INTEREST}

All authors declared that there are no conflicts of interest.

\section{REFERENCES}

1. Goodman LS, Gilman A, Brunton LL, Lazo JS, Parker KL. Goodman and Gilman's the Pharmacolohical Basis of Therapeutics. 12 $2^{\text {th }}$ ed. New York: McGraw-Hill; 2011.

2. Agency for Health Research and Development. Basic Health Research 2013. National Report; 2013. p. 1-384.

3. Kumar P, Sharma P, Sharma R, Tripathi GK, Gupta G. Assessment of microalbuminuria in essential hypertensives and its response to angiotensin-converting enzyme inhibitor therapy. Asian J Pharm Clin Res 2016;10:32-4.

4. Marusic VB. The incidence of potential drug-drug interactions in elderly patients with arterial hypertension. Int J Clin Pharm 2010;32:815-21.

5. Halevy S, Ghislain PD, Mockenhaupt M, Fagot JP, Bouwes Bavinck JN, Sidoroff A, et al. Allopurinol is the most common cause of stevensjohnson syndrome and toxic epidermal necrolysis in Europe and Israel. J Am Acad Dermatol 2008;58:25-32.

6. Iraz M, Kurcer Z, Ozdemir R, Guven A, Sezgin AT, Olmez E. Comparative effects of losartan and enalapril on serum digoxin levels in patients with congestive heart failure. Eur J Gen Med 2004;1:12-5.

7. Cleland JG, Dargie HJ, Pettigrew A, Gillen G, Robertson JI. The effects of captopril on serum digoxin and urinary urea and digoxin clearances in patients with congestive heart failure. Am Heart J 1986;112:130-5.

8. Makan H, Bangalore S, Desouza KA, Shah A, Messerli FH. Efficacy and safety of dual blockade of the renin-angiotensin system: Meta- 
analysis of randomised. BMJ 2013;360:1-15

9. Radosević N, Gantumur M, Vlahović-Palcevski V. Potentially inappropriate prescribing to hospitalised patients. Pharmacoepidemiol Drug Saf 2008;17:733-7.

10. Sharma S, Chhetri HP, Alam K. A study of potential drug-drug interactions among hospitalized cardiac patients in a teaching hospital in Western Nepal. Indian J Pharmacol 2014;46:152-6.

11. Sami PK, Jith A, Kumar CT, Joy JS, Kumar RS. A prospective study of drug-drug interactions and adverse drug reactions among stroke patients in a tertiary care hospital. Asian J Pharm Clin Res 2016;9:100-4.

12. Baxter K. Stockley's Drug Interactions. London, UK: Pharmaceutical Press; 2010. p. 2-11

13. Antoniou T, Gomes T, Juurlink DN, Loutfy MR, Glazier RH, Mamdani MM, et al. Trimethoprim-sulfamethoxazole-induced hyperkalemia in patients receiving inhibitors of the renin-angiotensin system: A population-based study. Arch Intern Med 2010;170:1045-9.

14. Nickels LC, Jones C, Stead LG. Trimethoprim-sulfamethoxazoleinduced hyperkalemia in a patient with normal renal function. Case Rep Emerg Med 2012;2012:815907.

15. Mozayani A, Raymon LP. Drug Interactions: Clinical and Forensic Guidelines. Jakarta: EGC; 2013.

16. Abbas S, Ihle P, Harder S, Schubert I. Risk of hyperkalemia and combined use of spironolactone and long-term ACE inhibitor/ angiotensin receptor blocker therapy in heart failure using real-life data: A population-and insurance-based cohort. Pharmacoepidemiol Drug Saf 2015;24:406-13.

17. Vonbach P, Dubied A, Krähenbühl S, Beer JH. Prevalence of drug-drug interactions at hospital entry and during hospital stay of patients in internal medicine. Eur J Intern Med 2008;19:413-20.
18. Venturini CD, Engroff P, Ely LS, Zago LF, Schroeter G, Gomes I, et al. Gender differences, polypharmacy, and potential pharmacological interactions in the elderly. Clinics (Sao Paulo) 2011;66:1867-72.

19. Sepehri G, Khazaelli P, Dahooie FA, Sepehri E, Dehghani MR. Prevalence of potential drug interactions in an Iranian general hospital. Indian J Pharm Sci 2012;74:75-9.

20. Vítovec J, Spinar J. First-dose hypotension after angiotensin-converting enzyme (ACE) inhibitors in chronic heart failure: A comparison of enalapril and perindopril. Slovak investigator group. Eur J Heart Fail 2000;2:299-304

21. Londhe SP, Joseph A, John J, Philip K, Philip L. To identify, evaluate, and analyze the possible drug-drug interactions in patients diagnosed as Type 2 diabetes mellitus with hypertension in a tertiary care teaching hospital. Asian J Pharm Clin Res 2015;8:169-74.

22. May M, Schindler C. Clinically and pharmacologically relevant interactions of antidiabetic drugs. Ther Adv Endocrinol Metab 2016;7:69-83

23. McGrowder D, Ragoobirsingh D, Dasgupta T. The effect of captopril on blood glucose, plasma insulin and bloos pressure via a nitric oxide-independent mechanism in an animal model. Diabetol Croat 2003;32:125-31

24. Murtaza G, Khan MY, Azhar S, Khan SA, Khan TM. Assessment of potential drug-drug interactions and its associated factors in the hospitalized cardiac patients. Saudi Pharm J 2016;24:220-5.

25. Notoatmodjo S. Health Research Methodology. Jakarta: Rineka Cipta; 2014.

26. Sivva D, Mateti UV, Neerati VM, Thiruthopu NS, Martha S. Assessment of drug-drug interactions in hypertensive patients at a superspeciality hospital. Avicenna J Med 2015;5:29-35. 